\title{
Algunas consideraciones sobre la relación entre prueba y verdad*
}

\author{
Michele Taruffo
}

\section{Enunciados fácticos}

A los efectos de iniciar el análisis, propongo tomar en consideración algunos enunciados, elegidos al azar entre los infinitos posibles:

(1) El 2 de enero de 2002 la Federal Reserve estadounidense redujo la tasa de interés en un $0,5 \%$.

(2) La tasa de interés preferente aplicada por la mayoría de los bancos chilenos, en diciembre de 2002, fue de un $6 \%$.

(3) Con fecha F el banco B compró por orden del inversionista I vales de prenda warrant por un valor de cincuenta millones de pesos.

(4) El adulterio repetido y manifiesto de A ha hecho imposible que continúe la convivencia conyugal entre A y B.

(5) El precio acordado entre A y B para la venta del bien X fue de diez millones de pesos

(6) El día $\mathrm{D}$ a la hora $\mathrm{H}$ en el lugar $\mathrm{L}$, A disparó a $\mathrm{B}$ una bala que le llegó al corazón y le provocó la muerte.

Expondré ahora algunas observaciones simples respecto a estos enunciados, subrayando elementos comunes así como algunas diferencias:

a) Las proposiciones expresadas por los enunciados (1)-(6) son todas declarativas. De hecho, los enunciados en cuestión pueden ser verdaderos o falsos; tienen como objeto circunstancias que, aunque puedan contener implicaciones valorativas y como podremos ver - son en alguna manera, social y culturalmente "construidas", pueden darse o no darse en el mundo de las experiencias concretas.

\footnotetext{
* Traducción de Maurizio Betti y Rodrigo Coloma. Revisión de Jordi Ferrer.
} 
b) Las situaciones descritas por los enunciados (1)-(6) son todas, de alguna manera, relevantes para la vida, la riqueza o el destino de muchas personas: muchísimas en el caso de los enunciados (1) y (2), algunas en los otros casos. Sin embargo, lo importante es que la relevancia de estas situaciones se manifiesta en la medida en que éstas se han producido realmente, es decir si los enunciados (1)-(6) son verdaderos. La cuestión es obvia pero merece una reflexión. Por ejemplo, la circunstancia descrita por (1) es importantísima para la economía mundial sólo si el enunciado (1) es verdadero; si es falso no se verifica ninguna consecuencia. Del mismo modo, la circunstancia descrita por (6) es importantísima para la suerte de A, el cual tendría que ser condenado por homicidio, pero naturalmente esta consecuencia se debe dar para A sólo si el enunciado (6) es verdadero; si no es verdadero, entonces A debería ser absuelto y permanecer libre.

En concreto, lo que cuenta verdaderamente no es la mera enunciación de (1)-(6) por alguien, sino el hecho que estos enunciados sean verdaderos o falsos. Si son verdaderos, cada uno de ellos produce una serie de consecuencias de distinta naturaleza; si son falsos, no se produce ninguna consecuencia o se producen consecuencias diversas. Por ejemplo, no es suficiente que la CNN cuente (1): si (1) no es verdadero (cualquier cosa que ello signifique), no sucede nada. Análogamente, no basta que B afirme (4): si (4) no es verdadero, no se dará el presupuesto de la separación conyugal por responsabilidad de A.

c) Dado que lo que importa respecto a la producción de determinadas consecuencias es si los enunciados (1)-(6) son verdaderos o falsos, los sujetos interesados (inversionistas, bancas, contratantes, cónyuges, partes procesales, abogados, jueces) deben establecer si uno $\mathrm{u}$ otro enunciado es verdadero o falso, como premisas de las acciones o comportamientos a seguir (decisiones financieras, contractuales, personales, judiciales). En síntesis, establecer la verdad o la falsedad de estos enunciados es un problema que puede plantearse, y puede ser resuelto, en cualquier ámbito de la experiencia, incluso en el del proceso. Los sujetos que, de cuando en cuando, deben resolver problemas relacionados con las consecuencias de las circunstancias descritas en (1)-(6) tratarán se supone- de comportarse de manera racional, de establecer con la máxima certeza si 
los enunciados en cuestión son o no verdaderos. Por ejemplo, el gran operador financiero que debe tomar decisiones sobre importantes inversiones tratará de establecer con certeza, posiblemente absoluta, si la $\mathrm{CNN}$ ha dado una noticia verdadera cuando ha afirmado (1), o si se trata de una noticia falsa o aún no confirmada.

d) Los enunciados (1)-(6) pueden ser relevantes en el contexto de un procedimiento judicial. Así, por ejemplo, (1) y (2) pueden ser relevantes para establecer la tasa que debe usarse para el cálculo de los intereses que A le debe a B; (3) sirve para establecer el monto de la deuda de $\mathrm{C}$ al banco $\mathrm{B}$; (4) sirve para establecer de quién es la responsabilidad de la separación; (5) sirve para establecer cuánto le debe el comprador al vendedor; y (6) sirve para establecer si A es o no culpable de homicidio. Esta relevancia puede darse o no en los contextos judiciales, y provocar diferentes consecuencias, dependiendo si (1)-(6) son verdaderos o falsos: está claro, de hecho, que la decisión que tomará el juez será diferente si es verdadero que el precio fijado es aquél que se indica en (5) o si (5) es falso porque el precio establecido era otro, y así sucesivamente.

e) El significado de todos los enunciados en cuestión sólo puede ser determinado de manera contextual. De hecho, para entender el sentido de estos enunciados es necesario conocer, o al menos presuponer, contextos específicos que, en todo caso son bastante especiales y muy complejos. Por ejemplo, para entender el significado de (1) se hace necesario considerar el contexto financiero norteamericano y la economía mundial; (2) tiene sentido solamente en el contexto de las relaciones bancarias; (3) tiene sentido sólo en el contexto del mercado de los llamados "derivados financieros"; (4) tiene sentido sólo en el contexto de las relaciones conyugales entre A y B; (5) tiene sentido sólo en el contexto de relaciones contractuales entre A y B; (6) tiene un sentido diverso dependiendo del fáctico general al que se refiera (por ejemplo: si A y B son soldados enemigos, y A mata a B durante un combate, esto no transforma a A en un homicida). Naturalmente, la relevancia de (1) y (6) puede depender también - y así sucede generalmente en el proceso- de los contextos jurídicos, que también determinan el significado de los enunciados en cuestión. 
El hecho que el significado de los enunciados sólo pueda ser individualizado desde el interior de determinados contextos, y que, por lo tanto, sea de varias maneras (más de una simultáneamente) context-laden, es muy importante para entender la naturaleza de estos enunciados y para definir en cada caso las coordenadas dentro de las cuales se puede establecer la verdad o falsedad. Sin embargo esta situación, es decir la relatividad contextual de los enunciados en cuestión, no quita que ellos sean relevantes en diferentes situaciones (procesales y extraprocesales), pero sobre todo no quita que su relevancia esté ligada con su propia verdad o falsedad. Esto es así, dado que - como ya se ha dicho- los enunciados no generan determinadas consecuencias por el hecho de haber sido declarados por alguien, sino por haber sido establecidos como verdaderos en el marco de un contexto de relevancia.

\subsection{La construcción de los enunciados fácticos}

La naturaleza y la relatividad contextual de los enunciados fácticos exigen un análisis más detenido, que sólo puede hacerse a partir de la premisa de que un enunciado fáctico nunca está dado por sí mismo en situación alguna, sino que es formulado por alguien en una situación concreta y, generalmente, con una finalidad específica. Respecto del propósito de la enunciación de un hecho se harán algunas observaciones más adelante, al hablar del contexto del proceso. Aquí es útil subrayar que la formulación de un enunciado fáctico deriva de la construcción del enunciado que realiza el sujeto que lo formula. Esta construcción es una actividad compleja, que en algunos casos conlleva operaciones diversas y complicadas, de las cuales el enunciado fáctico es sólo el resultado final.

Estas operaciones "constructivas" se pueden reagrupar sistemáticamente en varias categorías.

a) Ante todo, puede hablarse de construcción selectiva para hacer referencia al hecho de que cualquiera que formule un enunciado fáctico debe realizar una serie de elecciones mediante las que se excluye todo lo que no interesa incluir en el enunciado (en ese momento o a los efectos de las finalidades por las que es formulado), es decir, 
una infinita variedad de circunstancias, y expresa únicamente aquello que se considera relevante, esto es, pocas circunstancias y posiblemente simples. Esto es así frente a la infinita complejidad de la realidad y a su infinita descomponibilidad, frente a la infinita pluralidad de puntos de vista desde los que cualquier circunstancia puede ser observada, que a su vez produce lo que Susan Haack entiende como pluralidad de descripciones verdaderas de la realidad.

En el contexto del proceso entran en juego dos criterios de relevancia que operan como estándares de elección de la descripción del hecho que se enuncia: la relevancia jurídica y la relevancia lógica del hecho del cual se habla. La relevancia jurídica deriva de la calificación del hecho según la norma que se le aplique, a los efectos de la decisión. En consecuencia, es la norma (o mejor dicho: la abstrakte Tatbestand definida por la norma) la que opera tanto como criterio de selección de las connotaciones del hecho que se consideran importantes, como de exclusión de las innumerables connotaciones del hecho que no interesan a los efectos de su aplicación. Así, entre las innumerables posibles descripciones de aquel hecho, se selecciona aquélla que permite que el hecho sea jurídicamente cualificado según la norma aplicable (se habla de hechos jurídicos, principales, constitutivos, materiales, etc.). La relevancia lógica caracteriza aquellos hechos que no son jurídicamente calificados por norma alguna, pero que, sin embargo, pueden entrar en el proceso en la medida en que a través de su conocimiento se pueden extraer conclusiones útiles para demostrar la verdad o falsedad de un hecho jurídicamente calificado. En ese caso, el criterio de relevancia, y por lo tanto el contenido del enunciado que da cuenta de ese hecho - que se acostumbra denominar como secundario, simple, indiciario o circunstancial- está constituido por la formulación de una inferencia (de allí la naturaleza lógica de este concepto de relevancia) capaz de relacionar el hecho secundario con un hecho principal transformando al primero en la premisa de una conclusión referida al segundo. Entre las infinitas descripciones posibles de un hecho secundario, se elige entonces la que permita la formulación de una inferencia de ese tipo, excluyendo aquellas que no tengan dicha función. 
b) Se puede hablar, además, de construcción semántica del enunciado fáctico. Precisamente, el hecho de que sea un enunciado, es decir, una entidad lingüística dotada de un significado comprensible, implica que su formulación se realice usando correctamente un determinado lenguaje y sus reglas (gramaticales, sintácticas, lógicas). Entre los muchos lenguajes posibles y entre los muchos usos posibles de un lenguaje, la formulación de un enunciado fáctico conlleva elecciones muy precisas, con la finalidad de determinar la forma lingüística más oportuna y más eficaz para expresar el significado del enunciado. Entre ellas, una elección especialmente importante es la que se plantea entre el uso de términos descriptivos y el uso de términos valorativos. De hecho, es evidente que, aunque no cambie el referente empírico del enunciado, es decir el hecho material del cual se está hablando, el significado del enunciado mismo cambia dependiendo si se quiere expresar descripciones o valoraciones del mismo hecho. En el contexto de un proceso esta diferencia puede ser muy relevante, por ejemplo, para aplicar la regla según la cual el testigo no puede expresar valoraciones sino sólo comunicar su conocimiento; o bien respecto al problema de qué significa "probar" un enunciado de hecho según si se considera descriptivo o valorativo.

c) Se debe tener en consideración, además, la construcción cultural del enunciado fáctico. Cada enunciado relativo a la conexión entre eventos implica el uso de categorías de interpretación de la realidad en función de las cuales dichas conexiones se construyen y su significado cambia según las categorías que se utilicen para formularlo. Por ejemplo, una cosa es usar la categoría de causa en lugar de la de probabilidad para decir que $\mathrm{X}$ es consecuencia de $\mathrm{Y}$; otra cosa es hacer referencia a un espacio cartesiano en lugar de un espacio con $n$ dimensiones; otra es razonar presuponiendo una concepción lineal y discreta del tiempo en lugar de la curva espacio-tiempo, etc. La construcción específicamente cultural tiene que ver con el hecho de que los presupuestos éticos, políticos, consuetudinarios o religiosos a menudo juegan una función importantísima para determinar las modalidades con que un hecho se describe, imponiendo la selección inclusiva y exclusiva de los diferentes aspectos de ese hecho en función de sus significados culturales. Un musulmán y un católico pueden describir un hecho de manera, al menos, parcialmente distinta, del mismo modo que sujetos con 
orientación política diversa puede atribuir significados simbólicos diferentes al color de una bandera.

d) Finalmente, es necesario tener en consideración la construcción social del enunciado fáctico. Este tipo de construcción se vincula con el importantísimo fenómeno que Searle denomina "construcción de la realidad social", y que hace referencia a la llamada teoría de los hechos institucionales. Como es sabido, se trata de aquellos hechos cuya existencia y determinación no está en función de una referencia empírica o material directamente perceptible, sino más bien en función de contextos sociales que "crean" y definen determinados hechos. El ejemplo del dinero, que presenta Searle, es muy significativo, pero muchos otros hechos institucionales (como la mayoría de edad, el estatus familiar, la posesión de un título de estudios, etc.) se pueden definir solamente en función del contexto social (político, jurídico, económico e institucional) dentro del cual son concebibles como "hechos". Se puede afirmar que un hecho viene enunciado de un modo determinado en función de su ubicación en un contexto institucional. Por lo tanto, podemos decir que el enunciado incorpora la configuración institucional del hecho.

Los elementos relacionados con las diferentes dimensiones de construcción de un enunciado fáctico se pueden identificar en forma ágil en cualquier enunciado, incluso en los enunciados de (1) a (6) que han sido propuestos al inicio a manera de ejemplos. Respecto a ello no es necesario hacer aquí un análisis detallado, pero algunos comentarios pueden resultar útiles.

Por ejemplo, los enunciados (1), (2) y (3) se refieren a circunstancias que pueden considerarse "existentes" sólo en el mundo de las transacciones financieras, y que no se pueden encontrar en el mundo de la realidad empíricamente verificable. Aquí cobra utilidad el discurso de Searle respecto a las realidades socialmente construidas, en las cuales lo que cuenta no es el aspecto empírico (si es que existe, aunque no siempre existe o es perceptible), como el sonido, las imágenes, el papel escrito, etc., sino más bien el conjunto de convenciones, de conexiones y de símbolos, en función de los cuales, por ejemplo, un billete es dinero y no un simple pedazo de papel coloreado. 
Consideraciones en buena medida análogas, se pueden hacer también en relación con los demás enunciados. Por ejemplo, respecto a (4) se puede decir que el adulterio tiene una evidente connotación empírica (que aquí no es necesario describir en sus detalles); sin embargo, la practica de las relaciones sexuales entre A y C no es importante sino en un contexto social y éticamente construido en el cual dicho comportamiento es considerado moralmente de manera negativa (aunque muchas veces no sea castigado por el derecho penal), considerando así justificada la reacción negativa de $\mathrm{B}$, consistente en considerar intolerable la convivencia conyugal con A. En un contexto social, moral o religioso, en el cual una relación sexual con persona distinta del cónyuge tuviese la misma consideración que una cena en un restaurante con esa misma persona, no se podría hablar de adulterio y (4) no tendría sentido. El enunciado (5) tiene evidentemente una base empírica, en cuanto presupone que A y B hicieron declaraciones con cierto contenido, y tiene además implicaciones psicológicas (si se piensa que dichas declaraciones manifiestan la voluntad de A y B), pero queda claro que ello adquiere importancia sólo en esa particular realidad social y jurídicamente construida que es el mundo de las relaciones contractuales. En (6), finalmente, hay un elemento empírico especialmente evidente, que no es necesario explicar, pero es claro que el significado del enunciado no se puede reducir a simples hechos materiales: más allá del hecho de que también la medición y la determinación del tiempo (el día $\mathrm{D}$ a la hora $\mathrm{H}$ ) es fruto de una convención, es suficiente subrayar que el hecho narrado se define como tal con la condición de emplear la categoría de causa como principio de interpretación y de explicación de la conexión entre el comportamiento de A y la muerte de B.

Estos ejemplos no sólo sirven para confirmar que las circunstancias que pueden ser relevantes en un proceso pueden ser de la naturaleza más diversa, con grados "empíricos" o de "construcción" más o menos elevados, sino que muestran también que estas diferencias deben ser tomadas con cautela, al menos en el ámbito del discurso que aquí se está haciendo y que tiene que ver fundamentalmente con el problema de la prueba los hechos. Por un lado, parece evidente - como se ha tratado de demostrar sintéticamente - que todo enunciado fáctico es el resultado de complejas actividades de "construcción" que determinan su formulación y significado; por otro lado, sin embargo, todo lo anterior no impide que se pueda predicar la verdad o la falsedad del 
enunciado fáctico, y que, por lo tanto, pueda ser objeto de prueba en un proceso. Por dar un solo ejemplo, que será retomado más adelante: volvamos al enunciado (1), que se refiere a una realidad que se puede considerar fruto exclusivo de una compleja y sofisticada construcción social, en la cual los elementos empíricos (el sonido de un anuncio; el papel en el cual está escrito) son totalmente prescindibles. Ahora bien, el hecho de que modificar la tasa de cambio norteamericana produzca las consecuencias que produce sólo si (1) es verdadero, y no produzca consecuencias o las produzca diferentes si (1) es falso, persiste. El mismo análisis puede hacerse respecto de los otros enunciados que estamos considerando, independientemente del grado empírico o de "construcción social” o cultural que presenta cada uno de ellos.

\section{El contexto procesal}

Aunque, como ya se ha mencionado, el contexto del proceso judicial sea sustancialmente parecido a otros contextos en los cuales puede surgir el problema de establecer si (1)-(6) son verdaderos o falsos, resultará útil realizar algunos comentarios más específicos respecto al contexto procesal, destacando algunas de sus especificidades que lo hacen diferente a otras situaciones.

a) Un primer aspecto importante consiste en el hecho que en el ámbito del proceso la relevancia de los hechos ( $\mathrm{y}$, por lo tanto, de los enunciados a ellos referidos) se determina, en primer lugar, en función de las consecuencias jurídicas que les pueden ser atribuidas. Al respecto se habla, como ya se ha mencionado, de relevancia jurídica respecto de aquellos hechos que producen inmediatamente las consecuencias previstas por las normas jurídicas que a ellos se refieren. Hay que recalcar, no obstante, que estos hechos son específicos también en el sentido de que se introducen en el proceso sobre la base de opciones y decisiones particulares de determinados sujetos. Por ejemplo, en el proceso civil sólo se incorporan y asumen relevancia los hechos que las partes plantean como objeto de sus demandas y excepciones, en virtud de los principios que atribuyen a las partes y no al juez el poder determinar el objeto del proceso.

Además, como también se ha dicho ya, también se incorporan al proceso aquellos hechos que resultan lógicamente relevantes: a éstos no se les vincula directamente 
consecuencia jurídica alguna, pero de ellos se pueden extraer inferencias lógicas que pueden producir conclusiones respecto a la verdad o falsedad de los enunciados relativos a hechos jurídicamente relevantes. Por lo tanto, la relevancia jurídica es el criterio estándar principal en función del cual se determina, directa o indirectamente, cuáles son los hechos (o más bien, los enunciados a ellos referidos) que se "incorporan" al contexto procesal, ya sean hechos principales o secundarios, que pueden producir consecuencias en relación con los hechos principales. Criterios similares pueden ser también usados útilmente en otros contextos, en los cuales asuma importancia la calificación jurídica de una determinada situación; sin embargo, son típicos del contexto procesal.

b) En el ámbito del proceso se producen continuamente situaciones de contraste dialéctico en las que se formulan distintas narraciones a propósito de los hechos jurídica y lógicamente relevantes. Ahora, si se observa el proceso desde la perspectiva del principio de contradicción, puede ser concebido precisamente como un "lugar" típico de desencuentro y de conflicto entre narraciones diferentes $-\mathrm{y}$ a menudo en conflicto- $\mathrm{de}$ los mismos hechos. En otros términos, todo hecho puede ser objeto de enunciados diferentes y contradictorios (es decir: a cada enunciado se puede oponer otro diferente y contradictorio). En la situación-tipo los abogados de las partes narran hechos diferentes o narran versiones diferentes y opuestas del mismo hecho. Por ejemplo, para el abogado de A (5) es verdadero, pero (5) es falso para el abogado de B. Por razones análogas, un testigo presentado por A dirá que (5) es verdadero, mientras que un testigo presentado por B dirá que (5) es falso, etc. Naturalmente se producen situaciones procesales mucho más complejas, en las cuales cada una de las partes presenta su propia versión de los hechos (principales y secundarios, más o menos numerosos de acuerdo a cada caso), y cada uno de los testigos (que pueden ser incluso numerosos) narra su propia versión de los hechos. Además, estas versiones pueden cambiar durante el curso del proceso, cuando las partes modifican sus posiciones y a medida que se van practicando las pruebas. Si quisiéramos tomar en consideración la dimensión "verbal" o "narrativa" del proceso, como sugieren las teorías narrativistas, no podemos dejar de observar que el proceso no constituye una narración, sino que incluye una pluralidad de narraciones y de enunciados fácticos específicos, provenientes de diferentes sujetos (partes, abogados, 
testigos, peritos, jueces), que no sólo pueden tener como objeto circunstancias diversas (el testigo T1 habla del hecho X; el testigo T2 habla del hecho Y, y así sucesivamente), sino que en general están formadas por enunciados diferentes y opuestos respecto al mismo hecho (el testigo T1 dice que el hecho X sucedió; el testigo T2 dice que el hecho $\mathrm{X}$ no sucedió). Naturalmente, cada una de estas narraciones (o de estos pedazos de narraciones) puede ser verdadera o falsa. Sin embargo, ellas están presentes en el mismo contexto procesal y no forman, de ninguna manera, una sola narración coherente y omnicomprensiva. El proceso es un lugar de conflicto, de competición y de oposición entre posiciones diferentes $\mathrm{y}$, por lo tanto, también entre narraciones diversas de los hechos jurídica y lógicamente relevantes, en la específica situación de litigio; no es un lugar de cooperación entre varios sujetos que redactan una historia sobre cuyo contenido y veracidad se encuentran todos de acuerdo. Es más, cuando al final del proceso el juez determine que una de las versiones de los hechos de la causa es la "verdadera", no lo hará mirando simplemente qué narración global surgió del proceso, sino eligiendo, entre las diversas versiones que se formularon durante el proceso, aquella versión específica que considera preferible. Podríamos decir que al final del proceso el juez no se limita a constatar que surgió una versión de los hechos, como narración unitaria y coherente de los mismos, a partir de la convergencia de las narraciones formuladas por los sujetos del proceso, sino que resuelve el conflicto entre narraciones diversas, eligiendo una y descartando las otras como falsas e inaceptables. Éste es un aspecto del proceso judicial que las teorías narrativistas tienden a dejar de lado o a subvalorar, pero que, en cambio, es fundamental si se quiere comprender "quién narra qué" y cuántas y cuáles narraciones de los hechos componen la dimensión narrativa del contexto procesal.

c) Estas consideraciones nos llevan a poner especial atención en el acto final del proceso, es decir en la decisión judicial, como acto de elección entre las varias versiones de los hechos (entre los diferentes enunciados) que han marcado el desarrollo del proceso. Especialmente, y en lo que respecta a la narración de los hechos, se trata de establecer qué criterio usa el juez para elegir, entre las versiones opuestas ofrecidas por las partes, aquélla que, en cierto modo, representa el resultado del litigio procesal, o bien, si el juez mismo se construye una versión propia y diferente. Una respuesta obvia, que frecuentemente se da, es que el juez debería determinar cuál es la versión de los 
hechos de la causa que se puede considerar verdadera en algún sentido del término, descartando, pues, aquellas versiones que resulten falsas.

Sin embargo, existen opiniones bastante diferentes respecto al problema de si la verdad de los hechos (es decir, de los enunciados respectivos) puede o debe considerarse como una finalidad del proceso judicial. Por ejemplo, quien considera que la función del proceso es solamente poner término a la controversia, se inclina por excluir que éste tenga como finalidad la determinación de la verdad de los hechos Todavía más, la búsqueda de la verdad incluso puede ser vista como un obstáculo práctico para lograr rápidamente el objetivo consistente en eliminar la controversia. En cambio, quien considera que la función del proceso es aplicar la ley, poner en práctica el derecho y garantizar efectivamente los derechos individuales y colectivos, se inclina por configurar la determinación de la verdad de los hechos como finalidad o valor instrumental, al que se debe tender para acercarse al objetivo principal del proceso, entendido como la formulación de una decisión jurídicamente correcta.

Una de las maneras de configurar esta distinción tiene que ver el concepto de justicia: un concepto absolutamente incierto y complejo, pero que difícilmente se puede evitar cuando se habla del proceso como un modo de "administrar justicia". Desde esta perspectiva, un punto importante es establecer a qué se refiere la calificación de la decisión judicial en términos de justicia, es decir, qué se quiere decir cuando se habla de decisión justa.

Una primera hipótesis, que desde hace algún tiempo se ha ido difundiendo, basada en las doctrinas rawlsianas, es que para que exista una decisión justa es necesario y suficiente que sea el resultado de un procedimiento justo aplicado correctamente. Se trata, como es evidente, del concepto de pure procedural justice, en función del cual la justicia del procedimiento es el único elemento que determina la justicia del resultado. Este concepto tiene una gran fuerza explicativa y se aplica adecuadamente en diferentes contextos como el de los juegos, las apuestas y competiciones, en los cuales es ciertamente justo el resultado que se logra con la aplicación de procedimientos correctos. Esto también se usa en otros contextos, como en los procesos electorales o 
parlamentarios, en las relaciones internacionales y en la filosofía política, en los cuales — quizás por la extrema dificultad o por la imposibilidad de definir si una situación es justa o injusta según criterios substanciales - se hace coincidir la justicia de la solución con la justicia del procedimiento utilizado para alcanzarla. Desgraciadamente, este concepto tan fecundo no se puede aplicar con éxito en un contexto en donde el procedimiento tiene la máxima importancia, como es el caso del proceso judicial (que no por casualidad el mismo Rawls ubica en la categoría de la imperfect procedural justice). Evidentemente, esto no sucede porque en el proceso no tenga importancia la justicia del procedimiento: al contrario, se habla mucho de justicia de los procedimientos judiciales, por ejemplo, cuando se trata de definir las condiciones para un "debido proceso", en el sentido del art. 6 de la Convención de Salvaguardia de los Derechos del Hombre y de las Libertades Fundamentales (Roma 1950) o en el sentido del actual art. 111 de la Constitución Italiana (modificado por la ley constitucional $\mathrm{N}^{\mathrm{o}} 2$ de 2000).

La razón del fracaso es que la justicia del procedimiento puede considerarse, ciertamente, como una condición de justicia de la decisión (al menos en el sentido de que no estamos dispuestos a aceptar como justa una decisión tomada dentro de un proceso injusto, en el cual, por ejemplo: el juez no practicó pruebas o hubiese decidido tirando los dados o basándose en una confesión obtenida con la tortura), pero no puede ser considerada como la única condición, o como condición suficiente de la justicia de la decisión. Esto deriva esencialmente del hecho de que, sin menospreciar las numerosas metáforas del "proceso como un juego", el proceso judicial, de hecho, no es asimilable a un juego. Entre las muchas razones por las que un proceso no puede considerarse un juego, la más importante de ellas es que los procesos no terminan como los juegos, las apuestas o las competiciones, ni siquiera como terminan los procesos electorales u otros tipos de pure procedural justice. Un juego contiene en sí mismo (es decir: en sus reglas de procedimiento) el mecanismo que predetermina su resultado: la fijación de límites de tiempo, las formas en que se asignan los puntajes, las maneras como se formulan y asignan los votos, el orden de llegada, el jaque mate, o el impasse, etc. En todos estos casos no se necesita de nada más para determinar de quién es la victoria o la derrota, como tampoco se puede decir que la victoria es justa al igual como se dice que una 
decisión es justa (sólo para las barras es justa la victoria de su equipo, y sólo para el que gana es justo el resultado de la lotería, pero está claro que en este caso "justo" tiene un significado especial), como tampoco la derrota puede considerarse injusta.

El proceso en cambio, no tiene en sí mismo — es decir, en las reglas de procedimientomecanismo alguno que predetermine su resultado aunque, obviamente, el desarrollo concreto y específico de todo proceso condiciona de varias maneras el contenido de la decisión final (salvo el caso excepcional, que aquí no tiene importancia, que el proceso se interrumpa o se cierre con una sentencia que no resuelva el fondo del asunto). Un proceso "justo", es decir que se desarrolle correctamente en cuanto la aplicación de reglas procedimentales oportunas, no garantiza necesariamente una decisión justa. Se podrá decir que esta decisión es legítima desde un punto de vista formal, porque es el resultado de la correcta aplicación de las "reglas del juego", pero todo eso no implica necesariamente que la decisión sea también justa. La razón es que la decisión puede ser considerada justa sólo si se dan otras condiciones, que son consideradas conjuntamente necesarias y que están determinadas por el respeto de criterios substanciales de justicia.

El problema deriva del hecho que el proceso se termina con una decisión (no con el vencimiento de un plazo o con la constatación de quién llegó primero a la meta), y esa decisión proviene - al menos en los sistemas modernos en los cuales rige el principio de subordinación del juez a la ley_ de la aplicación de normas en los casos concretos que son objeto de decisión. En este sentido puede resultar útil el concepto de rule-based decision que Frederick Schauer elaboró en oposición al de particularistic decision, y que muestra muy bien el carácter esencial de la decisión judicial fundada en normas jurídicas.

Aplicar una norma en un contexto de decisión implica - como todos sabemosinnumerables problemas, que van desde la interpretación de la norma a la pluralidad de formas argumentativas con las cuales una norma puede ser utilizada en un caso concreto o mediante las cuales el caso concreto puede ser llevado al campo de aplicación de la norma. Estos problemas son importantes obviamente, pero no es necesario discutirlos en este momento. Aquí basta subrayar que la decisión judicial puede considerarse justa 
desde el punto de vista sustantivo sólo si deriva de la correcta aplicación de la norma jurídica (no importa si es legislativa, jurisprudencial, etc.) que rige el caso particular. En síntesis, se da una correcta aplicación de la norma jurídica al caso concreto sólo si:

1) la norma es adecuada para el caso y ha sido correctamente interpretada

2) se ha determinado la verdad acerca de los hechos que constituyen el caso.

La primera condición no puede ser discutida aquí porque remite a todos los innumerables problemas que afectan a la interpretación y la aplicación de la ley por parte de los jueces: supongamos, por simplificar, que el juez elija la norma jurídica que regula mejor el caso concreto, y la interpreta de la mejor manera.

En cambio, vale la pena subrayar que también la segunda condición es necesaria (aunque obviamente no es suficiente) para la justicia de la decisión. Para entender esta afirmación basta considerar que toda norma — especialmente, toda norma sustantivaconsiste en la atribución de consecuencias jurídicas para el caso de que se produzcan las circunstancias específicas previstas, en términos generales, por la misma norma. Para utilizar conceptos tan consolidados que se consideran obvios, se puede mencionar la abstrakte Tatbestand de la doctrina clásica alemana, o la fattispecie de la doctrina civil italiana o el "frástico" del que habla Hare, para hacer referencia a la parte de la norma en la que se formula la prótasis y se define la condición de hecho que debe darse para que se produzcan los efectos previstos por la norma (está claro que aquí se simplifica radicalmente el análisis estructural de las normas y del procedimiento para su aplicación, pero se mantiene el hecho que la típica norma sustantiva presenta esta estructura de fondo y se aplica cuando las definiciones abstractas del supuesto de hecho de la norma se corresponden con las circunstancias del caso particular).

Dado lo anterior, es evidente que si la norma $\mathrm{N}$ identifica el supuesto de hecho $\mathrm{H}$ como premisa necesaria para determinados efectos jurídicos, pero el hecho individual $h$ que corresponde a $\mathrm{H}$ no existe (en la medida en que es falso el enunciado que lo describe), entonces la norma $\mathrm{N}$ no puede ser aplicada en este caso. $\mathrm{Si}$, de todas maneras, el juez la aplica, ello basta para decir que la decisión no es justa. En términos positivos, esto 
significa que la decisión judicial es justa desde el punto de vista de la aplicación de las normas sustantivas sólo si es verdadero el enunciado referido a un hecho que constituye la condición de aplicación de la norma. Por otro lado, las modalidades con las que el juez formula la decisión no coinciden con el procedimiento que se desarrolló con anterioridad a la fase decisoria, y por lo tanto, la justicia de la decisión no puede coincidir con la justicia del procedimiento. De hecho, es obvio que a un proceso justo puede seguir una decisión injusta, si el juez se equivoca al interpretar la norma o si los hechos no se determinan correctamente porque el juez valora en modo equivocado el resultado de las pruebas.

\section{La prueba}

El proceso y, en particular, la decisión final, pretenden resolver la incertidumbre que se da respecto a la verdad o falsedad de los enunciados que tienen que ver con los hechos relevantes de la causa. La prueba es el instrumento que utilizan las partes desde hace siglos para demostrar la veracidad de sus afirmaciones, y del cual se sirve el juez para decidir respecto a la verdad o falsedad de los enunciados fácticos. En términos muy generales se entiende como prueba cualquier instrumento, método, persona, cosa o circunstancia que pueda proporcionar información útil para resolver dicha incertidumbre. Según esta definición, son pruebas tanto los instrumentos para adquirir información que están expresamente regulados por la ley (las denominadas pruebas típicas) como aquellos que la ley no regula expresamente (las denominadas pruebas atípicas) pero que, sin embargo, pueden servir para fundar la decisión sobre los hechos. Podemos agregar que, en términos generales, se pueden considerar como racionalmente admisibles todas las pruebas, típicas o atípicas, que sean relevantes en la medida en que aporten informaciones útiles para formular esa decisión; se excluyen del proceso sólo aquellas pruebas que, aún siendo relevantes, sean calificadas como inadmisibles por alguna norma jurídica especifica (como por ejemplo, las pruebas ilícitas o aquéllas para cuya adquisición habría que violar el secreto personal o profesional).

En este contexto se acostumbra a decir que la función de la prueba es la de ofrecer al juez elementos para establecer si un determinado enunciado, relativo a un hecho, es 
verdadero o falso. A su vez, se dice que un enunciado fáctico es verdadero si está confirmado por pruebas y es falso si las pruebas disponibles confirman su falsedad; y no está probado si en el proceso no se adquirieron pruebas suficientes para demostrar su verdad o falsedad. En función de cuál de estas posibilidades se dé, el juez decidirá de uno u otro modo y extraerá diferentes consecuencias jurídicas.

Estas cosas son obvias y ni siquiera valdría la pena discutir sobre ellas, si no fuere por su calidad de premisas para discutir un problema importante respecto de la naturaleza de la prueba judicial. Este problema deriva del hecho de que - simplificando mucho un panorama tremendamente complejo- parece que existen al menos dos concepciones fundamentales de la prueba judicial.

Según una primera concepción, la prueba es esencialmente un instrumento de conocimiento. Así, la prueba ofrece informaciones relativas a los hechos que deben ser determinados en el proceso. Por ejemplo, un documento "representa" una declaración y por lo tanto informa acerca del hecho respecto del cual la declaración ha sido tomada: (5) se demuestra como verdadero - al menos prima facie - si lo contiene un documento (y no se objeta la autenticidad del documento). Una grabación "representa" un hecho que se afirma que sucedió: (1) se demuestra como verdadero si la CNN transmite una grabación en la cual Alan Greenspan declara oficialmente la reducción de la tasa de interés (y nadie objeta la autenticidad de la grabación). Un testigo "declara" conocer determinados hechos: (6) se demuestra como verdadero si $\mathrm{T}$ declara haber presenciado el hecho tal como se describe (y nadie objeta la credibilidad del testigo), y así sucesivamente. Naturalmente, lo que se prueba puede ser también la falsedad de determinados enunciados: un documento puede contener una declaracion diferente de (4); una grabación puede mostrar a Greenspan negando cualquier variacion de la tasa de interés; un testigo puede decir que no ha sido A quien disparo a B, etcétera. En todo caso, se puede decir que la prueba es un instrumento que da informacion respecto al contenido de un enunciado, y da a conocer la circunstancia sobre la que versa el enunciado, con la consecuencia que el enunciado mismo puede considerarse verdadero o falso sobre la base de la prueba o las pruebas que a él refieren. A su vez, se puede decir que el hecho ha sido conocido, sobre la base de las pruebas que demuestran la 
verdad del enunciado correspondiente. Que este conocimiento (al igual que todo el conocimiento) sea relativo al contexto en el cual el hecho se conoce (el proceso) y sea, además, context-laden en los diversos sentidos que se indicaron anteriormente, no tiene especial importancia: nadie duda sensatamente de que en el ámbito del proceso no se establecen verdades absolutas y que cualquier conclusion que el juez extraiga del análisis de las pruebas depende de las pruebas que se incorporaron al proceso. Estas limitaciones, intrínsecas al contexto en el cual se usa la prueba judicial, pueden influir sobre el grado de verdad (o mejor dicho: sobre el grado de aceptabilidad, de probabilidad o de confirmacion) que puede ser atribuido a los enunciados fácticos, pero no excluyen que a través de las pruebas se determine la verdad o falsedad de estos enunciados y que, por lo tanto, se conozcan los hechos de los cuales se ocupan esos mismos enunciados.

De acuerdo con la segunda concepción, la prueba no sería más que un instrumento de persuasión, que como tal no tendría nada que ver con el conocimiento de los hechos. La prueba no serviría, pues, para establecer la verdad o falsedad de enunciado alguno y, por tanto, tampoco para proporcionar conocimiento acerca de nada, sino que serviría sólo para persuadir al juez, para convencerlo de lo fundado o infundado de un enunciado fáctico. La prueba, según esta concepcion, no ofrece información sino elementos de persuasión. Es decir, en el juicio no se "conocen" los hechos: todo se agota en los discursos y narraciones que se hacen en el proceso, y de esa manera se puede definir como verdadero el enunciado del cual el juez está persuadido, pero sólo en función del hecho de que realmente lo esté y afirme estarlo. Cualquier cosa que piense el juez, estando persuadido de ella, está probada y, por lo tanto, se puede considerar verdadera a los efectos del proceso. En el marco de una concepcion de este tipo, es extremadamente dificil ( $\mathrm{y}$, de todas maneras, totalmente inútil) analizar las características y la estructura de la prueba: de hecho, ella es compatible con (más aún, implica) una concepción irracional de la prueba judicial y, en todo caso, no exige que se dé una definición específica de la prueba. Dado que la persuasión de un sujeto respecto a cualquier cosa es de hecho un estado psicológico y nada más, la prueba puede ser cualquier cosa que hubiese influido en la formacion de este estado psicológico y tiene valor en la medida en que haya producido ese efecto, no por otras razones. Por otra 
parte, la persuasión puede deberse a cualquier causa, no sólo a la producción de pruebas en sentido estricto, por lo que resulta más bien ocioso preguntarse en el plano teórico qué es una prueba. Todo el problema se reduce a constatar ex post si el juez está o no persuadido de la verdad o falsedad de un enunciado. No se puede siquiera discutir si el convencimiento del juez es correcto o equivocado, porque ello presupondría una teoría prescriptiva o normativa de la prueba y del convencimiento del juez, mientras que las persuasiones no son correctas ni equivocadas, ni verdaderas o falsas: simplemente existen o no en la mente del juez.

$\mathrm{Al}$ respecto se puede observar que la prueba, como en el cuento de los dos ciegos que tocan a un elefante y uno cree que es un árbol y el otro una serpiente, es un fenomeno bastante complejo, de modo que no nos puede sorprender que se describan y se representen diversos aspectos a partir de diferentes puntos de vista. Sin embargo, hay que señalar que las dos concepciones hasta ahora individualizadas no son equivalentes entre ellas, y mucho menos intercambiables (tal como un árbol no es una serpiente).

En particular, respecto a la segunda concepción de la prueba, que podríamos denominar persuasiva, se puede decir que no es totalmente falsa, en la medida en que contiene algunos elementos de verdad. Sin embargo, es absolutamente parcial (y, por lo tanto, resulta falsa si se considera como la única concepción posible), ya que se corresponde típicamente con el punto de vista del abogado. En efecto, es especialmente el abogado quien usa las pruebas no con el fin de conocer o de comunicar conocimiento, sino con el fin de convencer al juez sobre la credibilidad de $s u$ versión de los hechos. El objetivo fundamental que persigue el abogado no es el de descubrir la verdad, o de tratar que el juez la descubra, sino el de ganar el caso. Puede decirse que el abogado puede estar verdaderamente interesado en descubrir la verdad en un solo caso: cuando la verdad de los hechos conduzca a la victoria de su cliente. En el caso opuesto, es decir cuando el descubrir la verdad podría llevar a la derrota de su cliente, el interés efectivo del abogado es que ésta permanezca en el misterio o que, en todo caso, el juez determine los hechos probados en un sentido favorable, aunque no sea verdadero. No es casualidad que el abogado no tenga ninguna obligación de presentar todas las pruebas de las que tiene conocimiento y menos aún aquellas que no favorecen a su cliente (pero que 
servirían para demostrar la verdad): tiene sólo el interés de presentar todas las pruebas favorables que posee. El único límite al comportamiento del abogado es que no puede hacer uso de pruebas cuya falsedad conoce.

Si bien éste es el punto de vista típico del abogado, no es el único punto de vista desde el cual se puede mirar el problema de la prueba y del conocimiento de los hechos y, tal vez, no es siquiera el punto de vista teórico más rico. Por otro lado, se puede observar que la pura y simple persuasión, desconectada de cualquier posible relación con el conocimiento, puede conducir a conclusiones falsas. Un testigo que parece muy persuasivo (tal vez porque, como requiere el tópico, es una mujer fascinante) puede hacer declaraciones falsas; un documento falso puede parecer auténtico y por lo tanto puede ser la base de la persuasión del juez. Sin embargo, las pruebas falsas ni siquiera son buenas para los abogados: están excluidas por ley y su uso consciente generalmente es castigado. Así pues, ni siquiera para el abogado es del todo irrelevante saber si la prueba ofrece informaciones verdaderas o informaciones falsas que podrían llevar al juez a convencerse de una versión errónea de los hechos.

El otro punto de vista importante es el del juez y, para dar cuenta de él, es mejor la concepción cognoscitiva de la prueba, presentada más arriba. De hecho, es verdad que el juez debe, de algún modo, "persuadirse" de la verdad o falsedad de un enunciado fáctico y, por tanto, no es completamente erróneo plantear que su convencimiento puede ser también fruto de la persuasión. Pero ello no agota de ninguna manera el problema. Por un lado, el juez debe fundar su decisión exclusivamente en pruebas admisibles. Por lo tanto, no es irrelevante cuál sea la fuente de su persuasión: si ésta deriva de informaciones extrajudiciales (la denominada "ciencia privada" del juez) o de pruebas ilícitas o inadmisibles, la decisión no se podrá basar en ellas sólo porque el juez las encuentre persuasivas. Por otro lado, el juez debe someter a control crítico las fuentes de su convencimiento (verificando la autenticidad y la credibilidad o la falsedad de la prueba), las inferencias que formula de un enunciado fáctico a otro (ya que los criterios de su razonamiento deben ser aceptables y lógicamente validos) y la fundamentación de las conclusiones que extrae (ya que sus elecciones deben estar racionalmente justificadas). Puede resultar entonces que el juez llegue a conclusiones que estén 
racionalmente fundadas en los elementos de prueba de que dispone, pero que estén en oposición con sus persuasiones personales basadas otras causas: en este caso, la persuasión subjetiva del juez no cuenta, y la decisión debe fundarse sobre la base de informaciones objetivamente controlables y de argumentaciones lógicamente válidas. A diferencia del abogado, el juez no tiene nada que ganar en la competición judicial, y no está (o al menos no debería estar) inclinado a hacer prevalecer una versión de los hechos y no otra, para favorecer el interés de Ticio o de Cayo: su punto de vista es el de quien debe tratar de alcanzar una decisión justa, en los términos indicados anteriormente.

Naturalmente, el sentido que debe atribuirse a la posición del juez depende de cómo se conciba la función de juzgar. Si se sostiene, como hacen muchos, que el juez sólo tiene el rol de un árbitro pasivo en el debate de las partes, con la única función de sancionar las violaciones a las reglas del juego, entonces no se espera que el juez establezca la verdad de los hechos (en ningún sentido del término). En este caso, es díficil (sino imposible) explicar cómo puede hacer el juez para formular la decisión y cuál es la función de la prueba: es justamente en el vacío conceptual que aquí se produce donde encuentra espacio la concepción persuasiva de la prueba. Si no se sabe cómo decide el juez (ni se le prescribe decidir según criterios determinados) y no se sabe cuál es el resultado de la prueba, se puede conjeturar que ésta sirve únicamente para persuadir al juez y que éste termine considerando verdadero sólo aquello de lo que se está persuadido. Resulta claro, sin embargo, que en este ámbito no hay espacio para ninguna teoría de la decisión justa: además, si se piensa que la función de la decisión es simplemente poner término a la controversia, y que ese es la finalidad fundamental del proceso, no tiene importancia si la decisión se funda o no en enunciados fácticos verdaderos, como tampoco si se aplican o no de manera apropiada las normas jurídicas que regulan el caso. En el proceso, entendido como libre competición entre las partes, en el cual el juez tiene sólo una función equivalente a la de un árbitro deportivo, gana, por definición, el más hábil o el más fuerte, no aquél que tendría razón sobre la base de los hechos y de las normas jurídicas.

$\mathrm{Si}$, en cambio, se considera que el juez, además de gobernar el proceso, es el garante de la correcta aplicación de la ley y que tiene la tarea fundamental de asegurar la tutela 
efectiva de los derechos, entonces el acento se traslada necesariamente hacia los criterios en función de los cuales el juez formula su decisión. Desde esta perspectiva, se espera que ésta no sea "cualquier decisión”, que resultaría aceptable si el interés fuera lograr poner término "de cualquier manera" al litigio, sino que sea una decisión justa en el sentido definido anteriormente. Esto implica que la decisión resulte de la correcta aplicación de las normas jurídicas que regulan el supuesto de hecho, pero la correcta aplicación de la ley en el caso concreto implica — como ya hemos visto- que hayan sido determinados los hechos "adecuados", es decir que se haya establecido la verdad o la falsedad de los respectivos enunciados a partir de las pruebas disponibles.

En la práctica judicial la función cognoscitiva y la función persuasiva de la prueba se entrecruzan de varias maneras en función de los diferentes contextos procesales concretos, con el resultado de que puede incluso hacerse dificil distinguirlas. En el plano teórico parece, de todas maneras, evidente que la concepción persuasiva no agota la función de la prueba y sólo consigue poner de relieve algunos aspectos de su uso forense. La concepción cognoscitiva, en cambio, identifica exactamente la función de la prueba, que está directamente relacionada con la función del juez tal cual se define en los sistemas que exigen que la decisión sea "justa en los hechos" y no sólo en el derecho.

\section{Prueba y verdad}

Como se ha señalado ya anteriormente, el problema de la verdad o falsedad de los enunciados fácticos se plantea en contextos muy diversos, en los cuales del hecho de que un enunciado sea verdadero o falso se extraen consecuencias relevantes. Es el caso de los enunciados (1)-(6) analizados al comienzo, ya que la verdad o falsedad de cada uno de ellos puede ser relevante en varios contextos y para varios efectos, pero sucede exactamente lo mismo en otros innumerables casos. Como también se ha visto, este mismo problema se plantea en el contexto del proceso, donde la verdad o falsedad de un enunciado fáctico es relevante, de forma que se hace necesario probar si dicho enunciado es verdadero o falso. 
Se acostumbra a decir (como ya se mencionó anteriormente) que el contexto del proceso es peculiar por muchas razones: porque hay reglas de exclusión de cierto tipo de pruebas, porque a veces hay normas que determinan a priori el valor de ciertas pruebas, porque interest rei publicae ut sit finis litium de tal forma que la búsqueda de la verdad no puede durar indefinidamente, etc. Estas observaciones son correctas, a pesar que su significado cambia mucho de un proceso a otro, pero no excluyen en absoluto que también en el proceso se tienda a establecer la verdad de los hechos por medio de las pruebas, de una forma substancialmente similar a cuanto sucede fuera del proceso. De hecho, tampoco en los demás sectores de experiencia se cuenta con todas las informaciones posibles, por las más variadas razones (incluso, por ejemplo, la necesidad de tomar en cuenta algunas normas que también fuera del proceso protegen la privacy individual y el secreto profesional), y se tiene también un límite del tiempo y de recursos para la búsqueda de la verdad de un hecho, cuyo conocimiento sirve para tomar una decisión ulterior. Sin embargo no se duda, a pesar de estos límites, de que la búsqueda de la verdad tiene sentido y que un decisor racional debe tender a maximizar la verdad de su conocimiento sobre los hechos que le interesan, si quiere maximizar la validez de sus decisiones y reducir el riesgo de errores que puedan traer graves consecuencias. Para dar un solo ejemplo entre los que ya se usaron, sería un pésimo decisor el asesor financiero que decidiera una inversión sin saber si (1) es verdadero o falso y, por tanto, sin tratar de buscar pruebas al respecto.

Obviamente, en el ámbito del proceso se puede hablar solamente de verdad relativa y context-laden, del mismo modo que se puede hablar de procesos más o menos orientados a favorecer la búsqueda de la verdad, pero también la relativización de la verdad opera en cualquier otro contexto de la experiencia (quizás con las únicas excepciones de la teología y la metafísica). Sin embargo, vale la pena precisar que el carácter contextualmente relativo de la verdad que se puede alcanzar en el proceso, no constituye una razón suficente para afirmar que en el mismo se puede solamente hablar de verdad como coherencia de la decisión final respecto del contexto procesal y de las enunciaciones o narraciones que en él se dan. 
Por una parte, en efecto, si se observan los enunciados y las narraciones de los hechos que se formulan en el proceso se descubre fácilmente - como ya vimos anteriormente - que provienen de sujetos diferentes, que tienen finalidades diferentes $\mathrm{y}$, sobre todo, que en la mayoría de los casos, son contradictorios entre ellos. Siendo ésta la inevitable estructura dialéctica del proceso, resulta bastante dificil establecer respecto a qué debería ser coherente la decisión final sobre los hechos para que se pudiera considerar como verdadera y en qué debería consistir ese nexo de coherencia. Se podría decir que la decisión debería ser coherente con las afirmaciones de las partes y con el resultado de las pruebas, pero ¿qué sentido puede tener todo eso en un contexto en que las partes hacen afirmaciones contradictorias y las pruebas, además, producen resultados divergentes y en conflicto?

Por otra parte, si se observa la coherencia interna de una narración específica, por ejemplo, la que el juez desarrolla en la sentencia, es fácil ver que la mencionada coherencia no garantiza de ninguna manera la justicia de la decisión. En efecto, existen narraciones perfectamente coherentes pero falsas: basta pensar en una buena novela con una estructura narrativa tradicional (sobre la cual nadie se pregunta si es verdadera, justamente porque se sabe a priori que no lo es) o en un testimonio falso presentado por un testigo especialmente hábil. Sin embargo, el proceso no necesita de narraciones fantásticas o falsas, aunque sean coherentes: la justicia necesita de narraciones verdaderas, aunque algunas veces sean incoherentes desde el punto de vista narrativo. Como mucho, se podría sostener que una narración coherente es más persuasiva que una incoherente y que, por lo tanto, sería preferible como fundamento para la decisión. Todo ello, sin embargo, presupondría la aceptación de algunas premisas dudosas: a) que la coherencia de la narración es verdaderamente un factor —o el factor principal - del carácter persuasivo de la misma; b) que en el proceso se dan narraciones coherentes o que sólo las narraciones coherentes pueden ser tomadas en consideración; c) que las pruebas sirven sólo para persuadir. Como se puede ver fácilmente, todas estas premisas son en realidad question begging.

Finalmente, si el único problema del proceso fuese el de ser un espacio en donde se formulan narraciones coherentes, ni siquiera tendríamos el problema de la prueba de los hechos: bastaría dejar hablar a los actores del proceso y luego determinar quién es 
coherente y quién no lo es. En ese caso, cada proceso terminaría coincidiendo con una pièce de teatro en la cual cada uno narraría lo que quisiera y como quisiera. Sin embargo, aparte del hecho que a menudo se trataría de una pièce especialmente larga y aburrida, hay que considerar que entre la justicia y la literatura existen, junto a similitudes superficiales que a menudo se exageran, diferencias radicales que no se deben perder de vista. En efecto, los criterios que se usan para interpretar y evaluar textos literarios son diferentes de los que se usan para establecer la justicia de la sentencia desde el punto de vista de su fundamento fáctico.

Resulta entonces que, a pesar de todas las dudas que se puedan tener respecto del concepto general de verdad como correspondencia, y todos los problemas que conlleva, este concepto de verdad es el único que resulta sensato en el contexto del proceso. Entre los muchos argumentos que se podrían mencionar en este sentido, vale la pena destacar especialmente dos.

El primer argumento es que la norma sustantiva que usa el juez como criterio para la decisión presupone que la konkrete Tatbestand (es decir el hecho jurídicamente calificado que es objeto de decisión) se haya verificado efectivamente fuera del proceso y de sus narraciones, es decir, en el mundo de los acontecimientos reales (empíricos, históricos, materiales, etc.). Si dicho hecho no se ha producido "en la realidad" no se puede aplicar la norma y, si se aplica, es suficiente para calificar como injusta la sentencia.

La segunda razón es que en el proceso se usan pruebas y que éstas no sirven para producir narraciones sino para proporcionar informaciones sobre acontecimientos que se conjetura que sucedieron fuera del proceso. En cierto sentido, la prueba es el nexo entre los discursos que se hacen en el proceso y los acontecimientos del mundo real: una película muestra "lo que sucedió"; una grabación permite oír "lo que se ha dicho"; un testigo veraz narra "lo que ha visto o escuchado" en el mundo de los hechos reales. Mediante este nexo el juez reconstruye "la realidad" de los hechos relevantes para la decisión. 
Vale la pena realizar un comentario adicional: las consideraciones que preceden tienen sentido en general, con independencia del tipo de hecho del cual se hable. En otros términos, la concepción de la verdad procesal como correspondencia con la realidad externa y, por lo tanto, como demostrabilidad en juicio mediante pruebas, es válida para todo tipo de hecho que el juez deba verificar. Es verdad que en muchos casos el juez no se enfrenta únicamente con hechos materiales empíricamente verificables. Los enunciados (1)-(3) son ejemplos especialmente claros de hechos cuya característica principal es — como ya hemos visto- que son socialmente construidos y se producen en contextos sociales extremadamente sofisticados y complejos, fuera de los cuales ni siquiera se podrían imaginar y mucho menos describir con enunciados declarativos.

Sin embargo, estos hechos particulares "suceden" fuera del proceso, en un mundo de fenómenos que no son irreales sólo porque han sido socialmente contruidos. Cualquiera que sea su naturaleza ontológica, la reduccion de la tasa de interés por parte de la Federal Reserve es un hecho de cuya existencia real dudarían pocos asesores financieros, en el caso de que tuvieran la prueba, con independencia de sus concepciones filosóficas fundamentales (en el caso de que tengan alguna). Si en una controversia comercial internacional es necesario establecer la entidad de intereses cuya tasa está vinculada a la tasa de interés americana, su reducción se considerará como un hecho importante que se ha producido (o no) en el mundo de los fenómenos financieros "reales". Se trata, pues, de un hecho al que se debe corresponder un enunciado procesal verdadero. En sentido inverso, un enunciado procesal que afirme que tal reducción se ha producido es verdadero sólo si, en el mundo "externo" de los fenómenos financieros, ésta se ha producido efectivamente. Consideraciones análogas se pueden hacer para todo hecho que sea social o culturalmente construido en su totalidad o parcialmente. Los hechos empíricos constituyen sólo el material bruto que se usa para las más diversas construcciones sociales, valorativas, simbólicas o de categorías.

Así, queda en pie la afirmacion de Searle que cada realidad construida socialmente presupone una realidad no construida socialmente. No es casual que el mismo Searle aconseja realizar un "acto concluyente de limpieza filosófica" consistente en concebir la verdad como correspondencia a la realidad, aunque sea con una actitud similar a la que 
Susan Haack denomina innocent realism. Se trata, en definitiva, de reconocer que el mundo real existe y que de él se pueden dar infinitas descripciones verdaderas, siendo su verdad reportable al mundo real.

En todo caso, también ante enunciados que afirman la existencia de hechos como los que hemos analizado, ciertamente no reducibles a una simple dimensión empírica, el juez debe establecer la correspondencia del enunciado con la realidad del hecho que se está describiendo. De hecho, para esto sirven las pruebas, tanto en el proceso como en cualquier otro ámbito de la experiencia. 